\title{
Observing Anxiety in the Foreign Language Classroom: Student Silence and Nonverbal Cues
}

\author{
Kate Maher, Kyoto University of Foreign Studies, Kyoto, Japan \\ Jim King, University of Leicester, Leicester, UK
}

\begin{abstract}
This study looked at multiple forms of silence and nonverbal cues of language anxiety in the foreign language classroom to explore their functions from the perspectives of students. Using the Classroom Oral Participation Scheme (COPS) developed by King (2013), 18 hours of observation produced data on learners' verbal and non-verbal participation behaviours in Japanese university EFL classes. The data was analysed using the COPS participatory categories. Three recurring forms of silent L2 behaviour were identified: short responses, use of L1, and non-talk. Semi-structured follow-up interviews were carried out with 14 students whose silent behaviour was observed and transcribed into a corpus of 43,711 words. In addition to facilitative functions of silence such as cognitive processing, interviewees reported using silence to navigate interpersonal interactions with their classmates and fear of negative evaluation by peers. Findings illustrate how anxious learners may limit social exchanges in the target language for image protection purposes. For example, some students used short responses to avoid revealing a different opinion to their partner that might lead to an awkward interaction. The results suggest that awareness of nonverbal cues and silent behaviour - with multiple forms and functions, should be explored further as an approach to detecting language anxiety in EFL contexts.
\end{abstract}

Keywords: student silence, language anxiety, nonverbal cues of anxiety, classroom observation, Japanese university foreign language classroom

Language anxiety arguably remains a major affective factor in language learning (Gkonou, Daubney, \& Dewaele, 2017), and this appears to be particularly true within the Japanese EFL context (King \& Smith, 2017; Shachter, 2018; Toyama \& Yamazaki, 2019). The large number of potential effects on a language learner and the complex combination of triggers illustrates the prevalence of language anxiety which can affect even proficient language learners (MacIntyre \& Dewaele, 2014). One factor that continues to make language anxiety relevant in SLA research is that students are not only dealing with content-specific 
anxiety related to linguistic knowledge and language competence; they may also have concerns about their social performance when using the target language in the classroom context. Therefore, in addition to triggers of content-specific anxiety, a foreign language student may also feel anxious about the interpersonal and communicative factors present in a language class (Cassady, 2010; Horwitz, Tallon, \& Luo, 2010). King (2014) defines the foreign language classroom as a highly social situation with its own particular social performance expectations that can inhibit learners who, in turn, seek refuge in silent behaviours.

King's (2013) study of silence within Japanese university foreign language classrooms emphasises that anxiety is a dominant variable amongst a host of other factors in this setting. Williams and Andrade (2008) found that almost as high as fifty per cent of students in this setting expected to experience anxiety whilst studying a foreign language. Similarly, in a study of affective variables, Tani-Fukuchi (2005) found that over one-third of Japanese EFL students reported no positive experiences at all learning English. Potentially, a large portion of students in a class will experience negative impacts on their performance, self-efficacy, and motivation (Effiong, 2016; Kondo \& Ying-Ling, 2004; Maftoon \& Ziafar, 2013; Matsuda \& Gobel, 2004; Nakane, 2007). So, how can teachers identify anxious students to support them? Although the Foreign Language Classroom Anxiety Scale created by Horwitz, Horwitz and Cope (1986) is a well-known and reliable instrument for measuring anxiety levels, the realities of the classroom mean that use of such instruments is not always a practical option. Furthermore, questionnaires may not always be able to detect anxiety due to the dynamic nature of this emotion (Gregersen, MacIntyre, \& Olson, 2017). Therefore, teachers need to be more reliant on their ability to perceive anxiety by observing students during learning activities on a moment-to-moment basis and be able to consider other cues when trying to detect language anxiety in the classroom.

\section{Literature Review}

\section{Observing anxiety in the classroom: Nonverbal cues}

There is evidence of universal facial expressions for certain emotions, including fear (Ekman 1970; Scherer, Clark-Polner, \& Mortillaro, 2011). In the classroom, studies on anxious language learners' nonverbal behaviours have produced similar findings. Gregersen (2005, 2007a, 2007b, 2009; Gregersen et al., 2017) has identified common cues which she has used to train teachers to perceive anxious language students in class. Recurring nonverbal 
signals include limited facial expressions in the brow area and the mouth, less use of gestures and a closed or rigid posture such as crossing their legs. Kayi-Aydar (2014) looked at students' body language during speaking activities to see if individuals leant forwards towards their partner and found that the students' posture - whether they moved their body to face their partner - was a cue of whether they felt comfortable to participate in a speaking activity, or not. Gregersen $(2005,2007$ a) also found that anxious language learners were less able to control their eye movements and were less likely to make eye contact. This finding is supported by studies conducted with people other than language learners. Compared to facial expressions and body movements, eye movements and emotional intensity displays are less voluntary and harder to control in some people when related to negative feelings (Jack, Garrod, Yu, Caldara, \& Schyns, 2012). This cue is likely to be familiar to language teachers who have worked with students that look everywhere but at them when they want to avoid speaking (Gregersen, 2007b, p.60). This evidence from both within and outside the field suggests that knowledge of nonverbal cues of anxiety is a useful and practical approach for identifying students experiencing language anxiety.

One consideration with nonverbal cues is that research shows there are cultural and individual variations in the degree to which people display and perceive emotional displays (Ekman, 1970), which Gregersen (2005) has acknowledged in her classroom studies. Relying on students' facial cues may make it hard for teachers to identify anxiety, therefore, other cues of anxiety in Japanese EFL classrooms should also be examined. Student silent behaviour is one such cue. It makes sense that someone who is nervous about speaking may speak less and want to avoid public utterances. Looking at student behaviour in the Japanese EFL classroom, it appears that silence is prevalent; students often hesitate to use the target language (Curry, 2014; Harumi, 2011; King, 2013; Shea, 2017). Studies by King (2013, 2016) emphasising the complexity of classroom silence demonstrate how low student oral participation can be, with as little as less than one per cent of initiated talk by students in one study (King, 2013). King observed multiple forms of student silence, and in follow-up interviews found that anxiety tended to be the dominant emotion linked with silent behaviour. Despite this, as King and Smith state (2017), silence is rarely put at the heart of investigations into anxiety, meaning there tends to be little awareness amongst educators of silent behaviour as a cue for anxiety. 


\section{Silence and anxiety in the Japanese foreign language classroom}

King's cognitive-behavioural model of a silent L2 learner's social anxiety (Figure 1) (King, 2014; King \& Smith, 2017) has identified a connection between silence and anxiety, highlighting the context-specific factors of the foreign language classroom in Japan. These include pedagogical factors that limit time in class for speaking practice due to a strong focus on vocabulary and grammar knowledge for high-stakes entrance exams (Gorsuch, 1998; Nishino \& Watanabe, 2008; Osterman, 2014; Shachter, 2018). Also, there is the influence of socio-cultural norms in the classroom where expected behaviour emphasises listening over speaking and is centred around the teacher talking and students listening (Aspinall, 2006; Peak, 1989). These in-class behavioural expectations can mean that student silence tends to be evaluated by teachers and peers as more appropriate than speaking during class (Nozaki, 1993). Previous studies have highlighted the influence of these attitudes (Effiong, 2016), showing that students worry that speaking will annoy or bother their classmates (Bao, 2014; Greer, 2000; King, 2013; Nakane, 2007).

King (2013) demonstrates how silence in the foreign language classroom can become an attractor state that can have negative repercussions for language learning, primarily when silence is used as a safety behaviour which can sustain feelings of anxiety. The more a student uses silence to avoid their feared predictions about speaking English to negotiate inclass oral participation safely, the more likely it is for them to remain in a negative cycle of thoughts, behaviour and emotions (Clark \& Wells, 1995; King, 2014). If a student is anxious about speaking, remaining silent would understandably have a short-term appeal as a means of avoiding feared situations. However, if the student does not test feared predictions, it will become increasingly hard for them to break out of this negative cycle and manage their anxiety. 


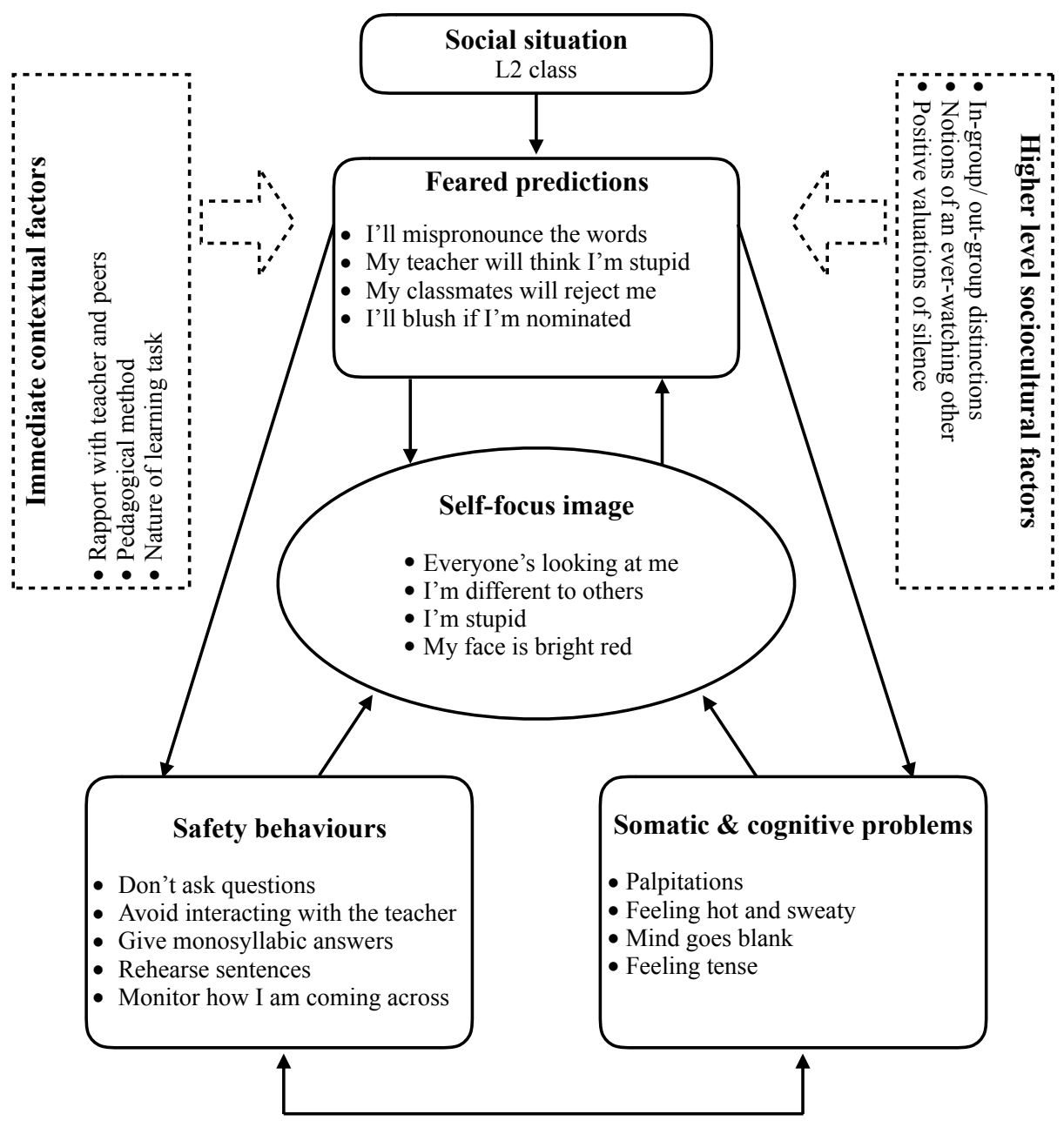

Figure 1: A Cognitive-behavioural Model of a Silent L2 Learner's Social Anxiety (King \& Smith, 2017, Adapted from King, 2014)

As most teachers know, however, it is uncommon for a learner to be entirely reticent in class, and the meaning of silence can vary depending on the context. King (2013) found in his large-scale observational study of 900 learners of various Japanese foreign language university classrooms that silence is not just the opposite of talk. Figure 2 is a visual representation of the continuum of speech-silence by Jaworski (1993) and provides an overview of the forms of silence observed in foreign language learning environments in previous studies (Bao, 2014; Gilmore, 1985; Harumi, 2011; Jaworski, 1993; King, 2013; McVeigh, 2002; Nakane, 2007; Peng, 2012; Saville-Troike, 1985; Tannen, 1985). This 
dynamic and anti-essentialist (Jaworski, 1993) view of silence allows for a more detailed description as multiple types of behaviour can be included as forms of student silence.

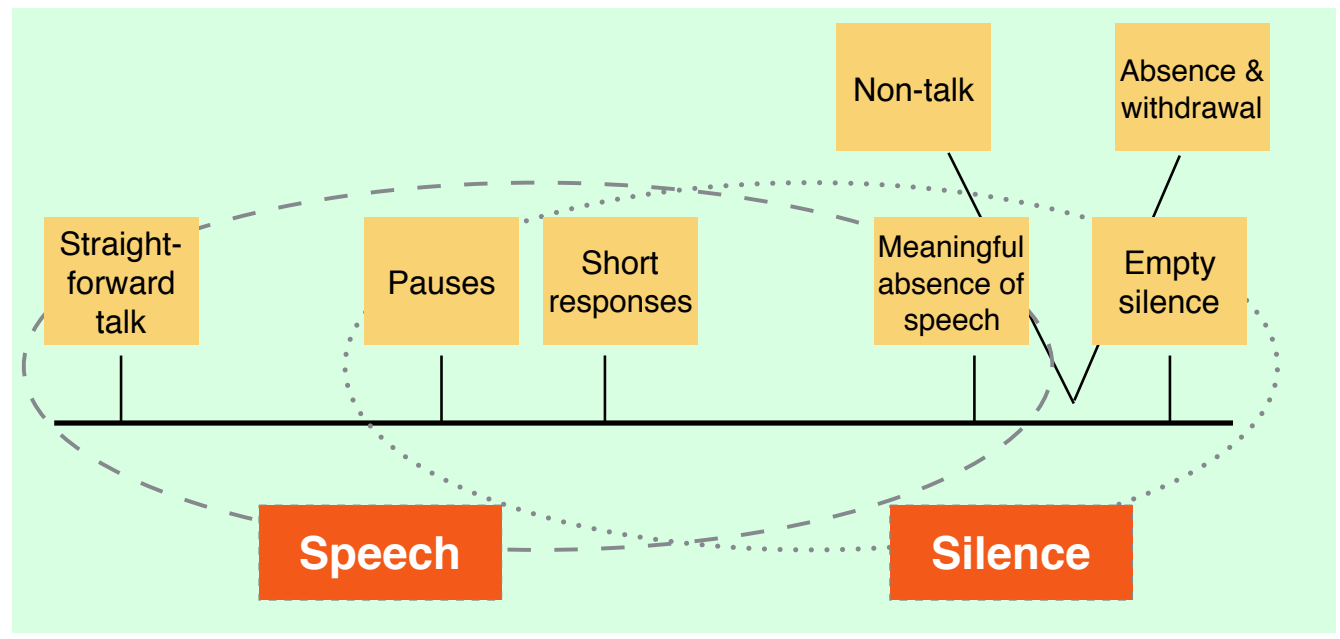

Figure 2: Continuum of Speech-silence

However, as Saville-Troike (1985) argues, silence is not always a meaningful communicative act; the student could be distracted thinking about something unrelated to class. Also, silence in the language classroom can be facilitative, signifying a moment of cognitive processing in preparation to speak (Bao, 2014; Kusaka, 2013). According to Sobkowiak's (1997) markedness theory, this type of silence could be described as unmarked silence as it does not cause the other person to attach any significance to the silent episode. When interpreting silence in the classroom, Sobkowiak's (1997) markedness theory is a useful approach for qualifying types of silence to focus on marked moments that might be related to anxiety resulting from the social norms in a given context. Marked silence is unexpected and noticeable, which could then affect communication. In terms of the classroom, marked silence could describe a moment when a student is expected to talk in English for three minutes but only gives a short response, spending the rest of the time not speaking or speaking in Japanese. Therefore, any examination of the role of silence as a cue should be inclusive of the multiple forms and context-dependent functions of silent behaviour.

Borrowing Scollon's (1985) metaphor, silence can represent a 'malfunction' in an interaction if interpreted by those who perceive talk with few pauses as being like a 'humming machine' that is working well. In the foreign language classroom, where students are generally expected to be vocally active to become proficient in the target language, some 
teachers, and students, may believe that a successful language lesson is like a humming machine and moments of silence are a malfunction. If a student's silent behaviour is related to anxiety about speaking in the classroom, the student may struggle in their language learning if their teacher, or they, react to the silence as a 'malfunction' and negatively attribute it to lack of ability or motivation to participate. Despite the potential impact of silent behaviour on language learning, its various forms and functions have not been covered extensively by existing theories of foreign language learning (King, 2013). This study aims to add to the existing knowledge of approaches to detecting language anxiety focusing on silence and nonverbal cues.

\section{The Study}

\section{Research aims}

This mixed-methods study was an exploratory examination of silence and nonverbal cues of anxiety in the foreign language classroom. The main aims were to investigate the forms and functions of student silent behaviour that may exist alongside common anxiety cues and examine the relationship between silence and anxious feelings. The project's initial phases identified students who displayed recurrent marked silent behaviour during class observations. This study sought to avoid simplistic views of silence in the classroom as 'nontalk' or non-participation to see ways in which potentially anxious students' participation was limited during speaking activities. So, in addition to looking at the frequency and the degree of silence, the observations looked for various forms of student silent displays. Having identified such students, the second part of the study was to gain an in-depth understanding of participatory behaviours and nonverbal cues by conducting follow-up interviews with some of the students. By asking the students about their perceptions of silent behaviour, it was hoped that the functions performed by silence in this context would be revealed. Having these insights would then make it possible to analyse whether a connection exists between this behaviour and the emotion of anxiety to see if, in some situations, silence does act as a cue.

\section{Context of the study}

This study took place at a medium-sized private institution with a university and junior college on campus located in a metropolitan area in Honshu, the main island of Japan. The study was carried out during the second term of the two-term academic year to try to reduce the effect of factors that might influence how students participate in classroom speaking activities such as first-term nerves. Eleven observations of six class groups of 
English classes were conducted, totalling 18 hours. The researchers avoided large lecturebased classes favouring smaller communication skills workshop-style classes so there would be more interactions to observe. A further consideration was having a balance of Japanese, non-native English speakers (NNEST), and non-Japanese native English speaker teachers (NEST). Harumi (2011) found in her study of Japanese EFL learners that they responded better to teachers who empathised with their in-class oral behaviour, including silence, which tended to be Japanese teachers. The proficiency levels of the students varied from intermediate to advanced (as determined by the institution's class placement levels). This group of learners were chosen for this study to investigate the potential effects of contextspecific factors of the foreign language classroom in Japan found in previous studies. Also, most of the participants were in their late teens to early 20 s which is an age when social anxiety is prevalent and can affect interactions with their peers and negatively impact learning (Topham et al, 2016). Ethical permission was granted by the gatekeepers and each participant before data was collected.

Table 1

Classes Observed

\begin{tabular}{|c|c|c|c|c|c|c|}
\hline Class code & $\begin{array}{l}\text { No. of } \\
\text { students in } \\
\text { class }\end{array}$ & Teacher & Major & Course & Year & $\begin{array}{l}\text { No. of } \\
\text { observations }\end{array}$ \\
\hline GS_01 & 23 & Male, NEST & $\begin{array}{l}\text { Global } \\
\text { Studies }\end{array}$ & $\begin{array}{l}\text { English speaking \& } \\
\text { listening skills (c) }\end{array}$ & 1 & $1 \mathrm{UNS}, 3 \mathrm{ST}$ \\
\hline TD_02 & 20 & Male, NEST & $\begin{array}{l}\text { Career } \\
\text { English } \\
\text { (junior } \\
\text { college) }\end{array}$ & General English (c) & 1 & $1 \mathrm{UNS}, 1 \mathrm{ST}$ \\
\hline NM_03 & 24 & $\begin{array}{l}\text { Female, } \\
\text { Japanese }\end{array}$ & $\begin{array}{l}\text { Non- } \\
\text { English }\end{array}$ & General English (c) & 2 & $1 \mathrm{UNS}, 1 \mathrm{ST}$ \\
\hline BA_04 & 27 & Male, NEST & English & $\begin{array}{l}\text { English speaking \& } \\
\text { listening skills (c) }\end{array}$ & 1 & $1 \mathrm{UNS}$ \\
\hline BA_05 & 19 & $\begin{array}{l}\text { Female, } \\
\text { Japanese }\end{array}$ & English & English for interpreters & $3 \& 4$ & $1 \mathrm{UNS}$ \\
\hline BA_06 & 16 & $\begin{array}{l}\text { Female, } \\
\text { Japanese }\end{array}$ & English & $\begin{array}{l}\text { English presentation } \\
\text { skills (c) }\end{array}$ & 1 & $1 \mathrm{UNS}$ \\
\hline
\end{tabular}

c - compulsory component of student's course; UNS - unstructured observation; ST - structured observation 
Journal for the Psychology of Language Learning, Volume 2, June 2020, pp. 116-141. ISSN: 2642-7001. $\mathrm{http}: / / \mathrm{www}$.iapll.com/journal

\section{Observations}

Three of the class groups were observed twice. The first observation was unstructured to look at students' participatory behaviours referring to Jaworski's (1993) continuum of speech-silence (Figure 2). Chronological notes were made of class episodes to record the instructions and interactions for each unit of activity (Richards, 2003; Wragg, 1999) to get an overview of the dynamics and expected behaviours of the class. Two types of students were selected to focus on in the second observation. Focal participants were chosen because they displayed unexpected silent participatory behaviour that could be interpreted as possible anxious nonverbal cues. Supplementary participants were chosen as they displayed expected communicative behaviour and no noticeable anxious body language as decided by the first author based on Gregersen's (2005) study. Due to the ambiguous and individual nature of the research phenomenon of this study, including participants that did not fit the assumed image of a silent and anxious language student was important to discover the unexpected and reduce assumptions. A further advantage of including them was that having the perceptions of classmates that were more confident to speak in class and had perhaps experienced working with anxious classmates in speaking activities could provide further, and perhaps alternative insights (Alvesson, 2011; Neale, 2016).

For the structured observations, the Classroom Oral Participation Scheme (COPS) (King, 2013) was used. This low inferential scheme has been used for examining student silence in the foreign language classroom. The layout made it possible to compare focal and supplementary participants' behaviours, as well as the majority of the class to see whether participants followed expected behaviour. The COPS was chosen to provide a quantitative perspective to the higher inferential unstructured observation data. By quantifying learner behaviours, it was hoped that it would be possible to see the degree and frequency in which they occurred and highlight any patterns for discussion in follow-up interviews.

After analysing the first two sets of COPS data, however, it became apparent that focal and supplementary participants were 'participating' in the activities, with little overt silent behaviour. Both were taking part in the speaking activities in English as expected, with no notable differences in the degree and frequency of their participatory behaviours. However, some patterns of behaviour emerged in the focal participants' data such as short responses, taking the listening role in group talk, and delayed starts in pair-work. As the quantity of silence was lower than their oral participation and there were no apparent differences between them and the whole class, the researchers decided to use the COPS to 
record marked behaviours for follow-up in the interview in order to explore the participant's perception of them. Although the researchers had intended to use the COPS for quantifying silent behaviours as used in previous studies (King, 2013), the resulting usage meant that they were able to generate rich descriptive details of participants in-class participatory behaviours.

\section{Interviews}

Fourteen interviews were carried out with six focal participants and eight supplementary participants. Where possible, one focal and one supplementary participant for each class was chosen. Out of the six focal participants, one student had studied abroad for one week, and another individual was intending to use English for work after they graduated. These two students both said that they tried to find speaking opportunities outside of class, such as campus mixer events with international students. Out of the eight supplementary students, five had studied, abroad ranging from two weeks to one year, and expressed intentions to use English for work after they graduated. The remaining three said that they were planning to study abroad soon. Interviews ranged from 25 to 90 minutes, with an average of 35 minutes. When invited to take part in an interview, participants were given an information sheet and an interview guide in Japanese with general questions about how they feel when speaking in class (King, 2013; Senior, 2006). The purpose of this was to try to put them at ease. Being asked to have an interview could make these participants feel nervous about why they were chosen or what they would have to do (King, 2013). Also, considering issues that can arise in cross-cultural interviews related to language barriers (Squires, 2009), reflective dialogue techniques by Kato and Mynard (2016) were used to try to make sure participants knew that the researcher understood them to reduce any language anxiety resulting from miscommunication. The majority of the interview schedule contained adapted items from existing instruments (Table 2). The interview format was based around nine hypothetical scenarios about speaking English in the classroom. 
Journal for the Psychology of Language Learning, Volume 2, June 2020, pp. 116-141. ISSN: 2642-7001. $\mathrm{http}: / / \mathrm{www}$.iapll.com/journal

Table 2

Instruments for interview items

Foreign Language Classroom Anxiety Scale (FLCAS), (Horwitz, Horwitz, Context specific \& Cope, 1986)

Managing your Emotions for Language Learning (MYE), (Gkonou \& Oxford, 2016)

\begin{tabular}{ll}
\hline $\begin{array}{l}\text { State-Trait Anxiety Inventory (STAI) } \\
\text { (Spielberger, Gorsuch, Lushene, Vagg, \& Jacobs, 1983) }\end{array}$ & General anxiety \\
\hline Liebowitz Social Anxiety Scale (LSAS) (Liebowitz, 1987) & $\begin{array}{l}\text { Social anxiety, avoidance } \\
\text { and fear }\end{array}$ \\
$\begin{array}{l}\text { Social Phobia Inventory (SPIN) } \\
\text { (Connor, Davidson, Churchill, Sherwood, Foa, \& Weisler, 2000) }\end{array}$ & \\
$\begin{array}{l}\text { Fear of Negative Evaluation (FNE) } \\
\text { (Leary, 1983) }\end{array}$ & \\
\hline
\end{tabular}

\section{Analysis}

The interviews were transcribed in full to examine all utterances and paralinguistic behaviour (King, 2013; Richards, 2003) and to review what was said and how the participants said it being mindful of other anxiety cues. A qualitative data analysis programme with a comprehensive codebook was used for consistency when analysing the corpus of 43, 711 words. In the first round of coding, interpretative codes were used to maintain an ongoing process of voicing the researcher's (first author) assumptions and generating alternative interpretations in preparation for the next round of analysis (Senior, 2006). In the second round, codes were based on categories of participatory behaviours from the COPS and Gregersen's nonverbal cues (2005). After these two rounds of coding, iterative categorisation (Neale, 2016) was used to summarise the data assigned to each code in both rounds to consider the best fit through constant comparison between the interpretative analysis and the analysis using the codes from the COPS and Gregersen's nonverbal cues.

\section{Results and Discussion}

In this section, there will firstly be an overview of the common forms of silence observed, followed by a joint summary of focal and supplementary participants' perceptions. Secondly, this section will look at a focal participant's behaviours and their perceptions of them and how they relate to their language anxiety experiences. Finally, an example unrelated to language anxiety will be discussed to provide an alternative perspective of the relationship between silent behaviour and nonverbal cues. 
To set the scene for the results, this part will introduce the activities, class organisation and expected behaviours observed. The majority of the activities were controlled tasks such as timed speaking and practice of target expressions. Activities that were less structured for original production of the target language included conversation time (freetalk), topic discussions set by the teacher, and question and answer tasks where students conducted short interviews with one another about a given topic. All of the classes featured a version of timed speaking. These activities challenged students to keep talking for a set amount of time; ranging from 90-seconds to answer an unknown question, to five-minute prepared speeches. In seven of the classes observed, timed speaking activities accounted for 40 to 70 minutes. Also, students were asked to collaborate and interact in English to complete textbook tasks and share answers for reading and listening tasks. The activities were mainly done in pairs and occasionally small groups of three to four people. For most of the observed activities, students did not choose which classmates they worked with. Teachers organised the pairs or groups, and the rotation of classmates for changing partners or group members. The primary expected behaviour for the activities was to speak in English. In most classes, this was explained by the teacher when setting up the activity and as follow-up reminders. So, in most cases, students were aware that they were supposed to speak English, how long to speak, what target expressions to use and which classmates to speak with.

\section{Forms of silent behaviour}

Short responses. Short responses (Gilmore, 1985; Jaworski, 2000; Nakane, 2007; Tannen, 1985) can be considered a form of silence when the expectation for more verbal content or elaboration was not fulfilled, for example, single-word responses when a sentence was expected, or not fully disclosing information that was requested. Participants' behaviour was coded as a short response when an individual student, pair or group finished their speaking turn before the time goal set by the teacher, or before most of the other pairs or groups. As the teachers tended to explain how long students had to speak for in each activity, the COPS chronological approach to recording behaviour was useful for identifying short responses. Examples of this type of silent behaviour repeatedly displayed by the focal participants in the observations (i.e., recorded on more than one occasion for each participant) included: 
- Not reaching the goal in timed speaking: talking for 60 seconds when 90 seconds was the goal; giving a four-minute presentation when five minutes was expected, and a oneminute book talk when three minutes was expected.

- Finishing their talk before most other pairs by more than one minute during conversation time and discussion tasks.

- Asking the set question to their partner in discussion tasks or contributing one remark, and then not speaking for the rest of the activity.

Using Japanese. Students' use of Japanese was coded as silence when there was an expectation of English production in response to teacher instructions. The reasons for this were firstly that silence is not simply absence of noise; a person may choose to remain silent about certain topics or not produce talk in a particular language. Secondly, while there are evident advantages of L1 use for SLA, it has also been contended that in settings with limited opportunities to communicate in the target language in class, such as the context of this study, the learners may not always benefit (Nation, 1997). The researchers, therefore, wanted to investigate why participants reverted to using their L1 and whether this behaviour was related to language anxiety. This behaviour was coded when a student's dominant behaviour over one minute (in the same manner as selecting a category on the COPS) was speaking in Japanese whether they were discussing the activity or off-task. Moments when the focal participants often used Japanese and were recorded on more than one occasion for each participant included:

- During conversation time when both people, or the group, had finished their monologue about their topic, but the activity was not finished.

- Answering questions from their partner about the topic they had just spoken about.

- Returning to Japanese after the teacher, who was monitoring the speaking activity, walked away from their pair or group.

Non-talk. Longer types of silence that extend to beyond a pause are silences described as 'non-talk' (Jaworski, 2000). This type of silence can be differentiated from pauses as there is almost no talk integrated with the silence. The speaker is not vocally participating in the interaction or surrounding discourse, not initiating or responding, or not taking the role of the speaker as they are expected to (Nakane, 2007). In this study, behaviour was coded as non-talk if the student's dominant behaviour was not speaking when talk was 
expected: not speaking in English or Japanese when English was expected and most of the class were speaking or participating in the activity. This type of behaviour was observed during the following moments and recorded on more than one occasion for each participant:

- Checking answers alone in silence rather than collaborating with their partner.

- Writing in silence when talk was expected during conversation time and timed speaking activities.

- At the start of conversation time and discussion activities.

Marked silence was noticeable during less structured activities. These types of activities relied on the student's original production of the target language, as well as their ability to select the topic, make language choices, manage the amount of time that they spoke, and negotiate a two-way interaction more independently than the more controlled activities. In comparison with structured activities, conversation time, peer-feedback and question and answer sessions required the students to make more decisions about the interaction. This factor may have meant that the functions of these forms of silence could have been facilitative (Bao, 2014; Kusaka, 2013) to allow for cognitive processing. A further interpretation is the presence of language anxiety if the free nature of the activities led to uncertainty about how to behave, and their attention turned to the thoughts of their peers (Greer, 2000; King, 2014).

\section{Common themes from interviews with focal and supplementary participants}

Social context factors. All of the focal and six of the supplementary participants reported feeling affected by the silent behaviour of their partner, or group members, during speaking activities. This feeling was negatively modified when English was expected and the classmate they were working with used Japanese. Four of the focal and three of the supplementary participants revealed that they use more Japanese and less English in these situations, even when they were motivated to use English. One focal participant commented that, "if my classmate is speaking Japanese, I shouldn't speak English" and this situation tended to result in the marked silent behaviour of using their L1. Six of the supplementary students reported this pattern of influence as they experienced discomfort due to their partner's behaviour. One supplementary participant said that they feel awkward "when my classmate speaks Japanese and I want to speak English.” Students who experience less anxiety may be able to manage their feelings about this type of situation, and therefore, 
experience less discomfort or worry. This was demonstrated by the coping strategy of a supplementary participant, "I just talk to the teacher, or try to write down ideas for my next partner."

However, for two of the focal participants who shared this feeling, it triggered their anxious feelings due to their perception that they cannot control the situation and are distracted by their peers' thoughts and attitudes towards speaking (Greer, 2000; King, 2014). These findings reflect King's argument about how silent behaviour and anxiety can become connected as part of a negative cycle in his cognitive-behavioural model (2014). If an anxious student is silent or quiet with a partner, and their partner becomes silent as a result, the anxious student could read their partner's silent behaviour as a negative cue about their ability, leading to self-doubt and more silence. Also, this finding is similar to ideas from cognitive-behavioural theories of social anxiety where anxious behaviour can distance the other person, confirming or reinforcing the anxious person's negative perception about the situation and themselves (Clark \& Wells, 1995; Heimberg, 2002).

Reliance on teachers as social facilitators. Four of the focal and seven of the supplementary interviewees shared the view that they relied on their teachers to create an atmosphere for speaking English and wanted them to facilitate the social dynamics of the class. Once a speaking activity was underway, they explained that the teacher should facilitate the pair or group interactions by monitoring and helping keep students on track, particularly regarding the use of Japanese when English was expected. "If the teacher is monitoring, it is good to make us speak English more. If the teacher doesn't observe us, we speak Japanese." Some felt unable to change their partner's behaviour by leading the activity and speaking English themselves or suggesting that they (the pair) should use English. This finding illustrates that in some cases, the influence of peers is a stronger force on their participatory behaviours than the fear of poor academic assessment by their teacher (Bao, 2014; Greer, 2000; King, 2013).

For these participants, the role of the teacher went beyond facilitator of just activities, but also the interpersonal relationships between peers which they felt were necessary for participation in speaking activities. They felt that they needed the teacher to create opportunities for them to build interpersonal relationships with a variety of their classmates to make an atmosphere where it was easier for them to participate. "It's good to change pairs and speak to different people, and then we can make more friends. If there are more good 
relationships in my class, it is easier to speak English." One focal participant described his discomfort with the cliques that had formed in his homeroom class, and how he felt intimidated to speak in front of the class because he thought that the students in the other groups would negatively evaluate him. In this case, the negative influence of fixed groups forming in the class could have led to silent behaviour and speaking anxiety (King, 2013; King et al., 2020). In this example, it led to the participant using Japanese when English was expected and feeling helpless because he felt unable to escape from this situation, so silent behaviour was also a means of avoidance to reduce his anxiety regarding the negative evaluation by his peers. In his opinion, it is helpful if teachers make students change partners or groups regularly so that there are opportunities to develop relationships with different classmates to improve the interpersonal dynamics in the class. This reflects the findings of King et al. (2020), that teachers need to facilitate good group and interpersonal dynamics rather than relying on the hope that the group will just 'click.'

Fear of making mistakes. Most of the interviewees - focal and supplementary expressed worries about making mistakes and not having enough vocabulary. However, what separated these groups was the degree to which they reported that these self-doubts influenced their participation and triggered a negative cycle of feelings and thoughts. Whereas supplementary participants reported more positive perceptions of making mistakes, such as "it is a good way to learn," "mistakes are normal," three of them were also slightly critical of students that allowed their participation to be influenced by it. "I know mistakes are not good, but how long can they (anxious students) wait to speak? Until they are perfect? But that is not real." Another commented that "I can't say anything really because my English isn't good enough to use for speaking, but I accept it. I can't wait for it to be good. I have to try now."

When asked what anxious students could do to feel better about making mistakes, most of the supplementary students said that they just needed to try speaking. However, some went on to explain that those types of students often avoid speaking and think that learning more vocabulary or studying for tests will help them. The latter point was confirmed by three of the focal students who said that the best way to overcome their anxiety was to have a better vocabulary range or better test score. One of the focal students said her self-doubt over her vocabulary knowledge was the primary trigger for her anxious feelings and why she avoided looking at her partner's face. She explained that: 
"I can't understand enough to talk to my partner because of my poor vocabulary. I probably can't understand enough to ask them a good question either, so, I should just

listen. I'm too ashamed to speak and show my low-level vocabulary."

If the social aspects of the classroom and speaking activities are triggers of language anxiety, a lot that underpins these worries appears to be the self-doubt about not being able to deal with the resulting responses from their peers, influencing their participation. Social factors in the Japanese university language classroom could intensify these self-doubts for some students and result in them using silent behaviour to avoid making mistakes due to fear of negative evaluation (King, 2014, 2016).

\section{An in-depth example of the interrelated nature of silence and anxiety}

This section will look at one focal participant's silent behaviour and their perception of it in depth. Yuri, a first-year Global Studies major, chose to enter this department because all of the content was delivered in English. Before the start of the interview, Yuri explained that she did not enjoy speaking English with her classmates. During the interview, she repeatedly referred to this point when explaining her feelings about participating in speaking activities. Unlike other focal participants, she did not mention worries about a lack of vocabulary or pronunciation. Also, Yuri was aware of her anxiety and able to verbalise how her behaviour was negatively related to her classmates. In four observations, Yuri's (a focal participant) marked silent behaviour included short responses during free-talk, timedspeaking and discussion activities. In timed-speaking, she typically spoke for one minute rather than the expected 90 seconds. She usually took the listener role in free-talk time for four of the five minutes on average. During discussions, Yuri would initiate the conversation by asking the question the teacher had written on the board, then switch to the listener role for the rest of the time. It was also frequently noticeable that her pair would finish earlier than others, with her head facing downwards and neither of them talking in English or Japanese. King and Aono (2017) described this type of nonverbal cue in their study, where they found that some highly anxious learners can close down becoming almost 'like stones'. The student remains in complete control of their bodily responses and is highly aware of them with increased monitoring of the self but comes across as unnaturally still.

Other patterns of body language emerged which suggested that, consciously or not, Yuri was managing interactions with her classmates during speaking activities. One example 
was how she would finish her speaking turn early, then look at her desk or check her smartphone. Yuri commented that if she does not know her partner, or feels that she cannot predict their reaction, her worries about the interaction intensify and she tries to avoid talking any further. She talked about how "it is hard to talk to someone when I don't know their background or their opinion. I can't imagine what we should say or what is OK to say to them. I don't want them to misunderstand me." This sequence of silent behaviour combined with physically turning away from her partner could be interpreted as her signalling that she has finished her speaking turn or has no intention to participate further in the activity. This finding is comparable to Kayi-Aydar's study (2014), who examined students' posture as a sign of their intention to speak with a partner. It may also be an example of how some people try to mask their feelings (Gregersen, 2005; Matsumoto, 1993).

Yuri described herself as someone who struggles to make eye contact with classmates during speaking activities, preferring to look at her desk, which she described as a 'safe' place, which Gregersen has documented (2005). By looking down, she can avoid her partner's facial expression, which she believed would reveal the awkwardness they feel about talking with her. Her concerns about bothering her partner concur with previous findings of how speaking could disturb classmates which inhibits them from speaking (Greer, 2000; King 2013). "If their face is worried, it means they can't understand. Also, I will make them confused or worried if I stop speaking or can't think of the word. If their response is not good, I get nervous, and I can't speak anymore." These worries combined with the eye contact cue have echoes of a language-related form of taijin kyofusho - a Japanese psychiatric disorder where the person has a fear of offending others through their social behaviour (Kirmayer, 1991) as well as a sub-category of it called jikoshisen-kyofu, which is the fear of eye contact (Hofmann, Asnaani, \& Hinton, 2010).

Yuri also talked about how anxious she feels when trying to read her partner's nonverbal cues. She expressed how it was hard for her to speak with confidence when her partner is quiet, looking down, or using their smartphone. This type of reaction made her nervous because she perceived it as a sign that it was her fault, and they are "just tolerating me and my poor English." While these are feared predictions, during the observations, it was noted on several occasions that after Yuri ended the interaction, her partner would also stop participating. This could be an example of how an anxious person can distance themselves from other people due to their fears, which results in the other person becoming distant, reinforcing the person's fears and anxiety (Heimberg, 2002). 
From observing her participation and listening to her perceptions of her behaviours and feelings in class, patterns emerged that demonstrate the interrelated nature of silence and anxiety in the classroom. Her anxiety about speaking often resulted in various forms and degrees of silent displays, along with nonverbal cues of anxiety. As her mind became occupied with worries, her verbal participation decreased. However, as the point about her trying to interpret her partner's silence shows, at times, Yuri's silent behaviour may have triggered or intensified her anxious thoughts.

\section{Yuma's experiences of anxiety in the language classroom}

This section will look at a focal participant whose perception of his in-class silent behaviours did not refer to language anxiety. In the interviews, both focal and supplementary participants described moments when their observed silent behaviour was unrelated to anxiety, such as feeling tired, bored with the topic, or they were thinking about something else. There were also moments of cognitive processing when they were preparing what they wanted to say or rehearsing it (Bao, 2014; Kusaka, 2013). One explanation not given by any of the participants for their silent behaviour was a dislike for English which McVeigh (2002) and King (2013) found in their studies of Japanese university students' in-class behaviours. As the participants in this study were English majors, it is likely they had a more positive disposition towards the language and were motivated to study it.

One focal participant who did not mention any of the reasons above, including language anxiety, was Yuma, a 19-year old first-year English major. His instructor reported that in the previous term, Yuma left the classroom during group work refusing to participate in the activity, resulting in students choosing who they worked with. In the class observation, and later confirmed by Yuma in the interview, he had created a safety zone for himself in the classroom. He sat alone near the front of the class in a row of four seats, with two empty rows behind him. He remained sitting alone for most of the class, with his head down, going ahead in the textbook, and reading aloud. Although he did not mention anxiety directly, Yuma revealed that he experienced other negative emotions about not feeling 'safe' in the classroom. He described how he did not trust his classmates and avoided group work due to his discomfort. A specific example he mentioned was how he disliked interacting with unfamiliar classmates who were not 'efficient' and preferred to choose his partners. That way he could work with peers that he considered to be his 'good teammates' and those that he felt were 'safe' and 'useful' for him. He explained that in the first term, the teacher had mixed 
people into different groups and pairs, but this had led to numerous uncomfortable situations where he felt his group mates were stopping him from achieving his learning goals because of their silent behaviours - non-talk and using Japanese. Like other participants, a trigger for his anxiety was when his partner used Japanese when he wanted to use English, and he felt powerless to change their behaviour. His worries reached the point where he would leave the classroom.

In Yuma's case, the social aspects of the classroom were causing him anxiety as they conflicted with his learning goals. Yuma's emotions and behaviour resemble some of the elements of psychological safety (Edmondson, 1999). This construct is the shared beliefs of a team that the team is safe for interpersonal risk-taking and the relationship with learning behaviours and performance. Although this construct has been used to examine effectiveness of team learning in work settings, similarities exist between the two environments: the team of colleagues are classmates, the manager is the teacher, and the shared organisational goal is learning English. If a team member feels reliant on his team members to achieve a learning goal but perceives that his team members' behaviours are not conducive to achieving it and the team does not provide an effective learning context, negative emotions, such as anxiety, may arise and lead to silent behaviour in the form of withdrawal from the classroom (McVeigh, 2002).

\section{Conclusion}

Through using a classroom observation approach, this study has examined forms of silence and nonverbal cues for detecting anxiety in the Japanese university foreign language classroom. Interviews with the students about their perceptions of their silent behaviour and experiences of language anxiety revealed that in some cases, silent displays, such as short responses, using Japanese, and non-talk, are interrelated with their anxious feelings about speaking English in the classroom. The responses of the participants suggest that not only are negative thoughts and emotions inhibiting their in-class participatory behaviours, but their silent behaviour can also affect their emotions and thoughts when they perceive silence as worrying. This can result in an ongoing two-way negative cycle.

Although this study only examined a limited number of classes and participants, distinct themes linking student silence and anxiety became apparent: social context factors, teachers as facilitators of social interactions, and fear of making mistakes. The common thread connecting these themes is the social performance aspects of the classroom. What 
makes this finding significant is that both focal and supplementary participants raised these themes. This indicates that students who are confident about speaking and often participate in speaking activities, as well as students who experience anxiety and may participate less, can be influenced by the reciprocal effect of anxiety-related silence in the social environment of the classroom. The 'domino' effect of anxiety-related silence can mean that it is not just the anxious and silent student whose learning behaviours are impacted, but also those around them. This finding emphasises the importance of more awareness of silent behaviour in addition to nonverbal cues for detecting and understanding anxiety in the foreign language classroom. Future development of this study could modify Gregersen's study (2007) which looked at teacher's ability to use nonverbal cues to detect student anxiety and include multiple forms of silent behaviour to see whether this aided accuracy.

Silent behaviour often observed in this study was focal participants ending their speaking turn sooner than expected. In future studies, it would be worthwhile to seek out classes with more discussion-based activities with less structured turn-taking. In these activities, it might be possible to identify other types of silence; for example, hesitant starts to speaking turns in an interaction and whether this is a nonverbal cue of language anxiety. The researchers did not notice this behaviour in the present study which is perhaps due to the amount of timed-speaking activities where students started their speaking turns according to signals from the teacher. However, in the follow-up interviews, two focal participants (including Yuri) spoke about their hesitation to begin their speaking turn due to being distracted by reading their partner's nonverbal cues. Repetitions of this study could investigate the effect of response latency, which Gregersen and MacIntyre (2017) discuss as a nonverbal cue in language learners. A study could look at how long it takes a student to begin their speaking turn and how delayed starts affect students' thoughts and emotions about speaking. It could also examine how delays influence their partner's behaviour due to any discomfort resulting from perceived slow starts. King and Aono's (2017) cross-cultural study found little difference between British and Japanese students' discomfort level of silence. However, this was in one-to-one interactions with a teacher in a tutorial setting not in a class.

In the Japanese context, socio-cultural interpretations and roles of silence should be considered to take into account the cultural influences on learners' perceptions of silence. For example, Lebra (1987) distinguished four types of silence in her study of the significance of silence in Japanese communication; truthfulness, social discretion, embarrassment and defiance. Also, Peak (1989) described how listening is emphasised over speaking when 
Japanese children are socialised from a young age in educational settings, indicating that perhaps they may not attach any significant to silence in classroom interactions. Although cultural considerations are important, the context where the silence takes place is highly significant (Nakane, 2007). In a Japanese university foreign language classroom where every student is a language learner and likely to be from similar learning backgrounds, in what ways do different forms of silence affect them?

Some limitations of this study include the number of times that a class group was observed, and the number of participants interviewed. The researchers feel that the chance to observe the same group of students more than twice over an extended period could have produced more insights. For example, how did these participants' behaviours change in different in-class situations, with different classmates, and as the academic term progressed? Also, being able to interview more focal and supplementary students from each class group may have resulted in a better understanding of the dynamics of the class and other influences on in-class behaviours through the perceptions of more students. Furthermore, alternative methods for recording and analysing the observations could be investigated. In this study, paper instruments and a digital-voice recorder were used. However, considering that this approach focused on visual cues, video recording equipment could be more effective (see Wragg, 1999, for a discussion of the options). This time, the gatekeepers did not permit the use of cameras. Regardless of what approach is used, any researcher examining these phenomena must carefully take into account the impact their methods and role as the researcher could have on potentially anxious people.

\section{References}

Alvesson, M. (2011). Interpreting interviews. London, UK: Sage Publications Ltd.

Aspinall, R. W. (2006). Using the paradigm of 'small cultures' to explain policy failure in the case of foreign language education in Japan. Japan Forum, 18(2), 255-274.

Bao, D. (2014). Understanding silence and reticence: Ways of participating in second language acquisition. London, $\mathrm{UK}$ : Bloomsbury.

Cassady, J. C. (Ed.) (2010). Anxiety in schools: The causes, consequences, and solutions for academic anxieties (Vol. 2). New York, NY: Peter Lang.

Clark, D. M., \& Wells, A. (1995). A cognitive model of social phobia. In R. G. Heimberg, M. R. Liebowitz, D. A. Hope \& F. R. Schneier (Eds.), Social phobia: Diagnosis, assessment and treatment (pp. 69-93). New York, NY: Guilford Press. 
Curry, N. (2014). Using CBT with anxious language learners: The potential role of the learning advisor. Studies in Self-Access Learning Journal, 5(1), 29-41. doi:10.37237/050103

Edmondson, A. (1999). Psychological safety and learning behaviour in work teams. Administrative Science Quarterly, 44(2), 350-383. doi:10.2307/2666999

Effiong, O. (2016). Getting them speaking: Classroom social factors and foreign language anxiety. TESOL Journal, 7(1), 132-161. doi:10.1002/tesj.194

Ekman, P. (1970). Universal facial expressions of emotion. California Mental Health Research Digest, 8(4), 151-158.

Gilmore, P. (1985). Silence and sulking: Emotional displays in the classroom. In D. Tannen \& M. Saville-Troike (Eds.), Perspectives on silence (pp. 139-162). New Jersey, NJ: Ablex Publishing.

Gkonou, C., Daubney, M., \& Dewaele, J. M. (Eds.). (2017). New insights into language anxiety: Theory, research and educational implications. Bristol, UK: Multilingual Matters.

Gorsuch, G. J. (1998). Yakudoku EFL instruction in two Japanese high school classrooms. JALT Journal, 20(1), 6-32. Retrieved from https://jaltpublications.org/sites/default/files/pdf-article/jj-20.1-art1.pdf

Greer, D. L. (2000). "The Eyes of Hito": A Japanese cultural monitor of behaviour in the communicative language classroom. JALT Journal, 22(1), 183-195.

Gregersen, T. S. (2005). Nonverbal cues: Clues to the detection of foreign language anxiety. Foreign Language Annals, 38(3), 388-400. doi:10.1111/j.1944-9720.2005.tb02225.x

Gregersen, T. S. (2007a). Breaking the code of silence: A study of teachers' nonverbal decoding accuracy of foreign language anxiety. Language Teaching Research, 11(2), 209-221. doi:10.1177/1362168807074607

Gregersen, T. S. (2007b). Language learning beyond words: Incorporating body language into classroom activities. Reflections on English Language Teaching, 6(1), 51-64. Retrieved from http://www.nus.edu.sg/celc/research/books/relt/vol6/no1/5164gregersen.pdf

Gregersen, T. S. (2009). Recognising visual and auditory cues in the detection of foreignlanguage anxiety. TESL Canada Journal, 26(2), 46-64. doi:10.18806/tesl.v26i2.414

Gregersen, T., \& MacIntyre, P. D. (2017). Optimising language learners' nonverbal behaviour: From tenet to technique. Bristol, UK: Multilingual Matters.

Gregersen, T. S., MacIntyre, P. D., \& Olson, T. (2017). Do you see what I feel? An idiodynamic assessment of expert and peer's reading of nonverbal language anxiety cues. In C. Gkonou, M. Daubney, \& J. M. Dewaele (Eds.), New insights into 
language anxiety: Theory, research and educational implications (pp. 110-134). Bristol, UK: Multilingual Matters.

Harumi, S. (2011). Classroom silence: Voices from Japanese EFL learners. ELT Journal, 65(3), 260-269. doi:10.1093/elt/ccq046

Heimberg, R. G. (2002). Cognitive-behavioural therapy for social anxiety disorder: Current status and future directions. Biological Psychiatry, 51(1), 101-108. doi:10.1016/s0006-3223(01)01183-0

Hofmann, S. G., Asnaani, A., \& Hinton, D. E. (2010). Cultural aspects in social anxiety and social anxiety disorder. Depression and Anxiety, 27(12), 1117-1127. doi:10.1002/da.20759

Horwitz, E. K., Horwitz, M. B., \& Cope, J. (1986). Foreign language classroom anxiety. The Modern Language Journal, 70(2), 125-132. doi:10.1111/j.1540-4781.1986.tb05256.x

Horwitz, E. K., Tallon, M., \& Luo, H. (2010). Foreign language anxiety. In J. C. Cassady (Ed.), Anxiety in schools: The causes, consequences, and solutions for academic anxieties (Vol. 2, pp. 96-115). New York, NY: Peter Lang.

Jack, R. E., Garrod, O. G., Yu, H., Caldara, R., \& Schyns, P. G. (2012). Facial expressions of emotion are not culturally universal. Proceedings of the National Academy of Sciences, 109(19), 7241-7244. doi:10.1073/pnas.1200155109

Jaworski, A. (1993). The power of silence: Social and pragmatic perspectives. California; CA: Sage Publications, Inc.

Jaworski, A. (2000). Silence and small talk. In J. Coupland (Ed.), Small talk (pp. 110-132). Harlow, UK: Pearson Education.

Kato, S., \& Mynard, J. (2016). Reflective dialogue: Advising in language learning. New York, NY: Routledge.

Kayi-Aydar, H. (2014). Social positioning, participation, and second language learning: Talkative students in an academic ESL classroom. TESOL Quarterly, 48(4), 686-714. doi:10.1002/tesq.139

King, J. (2013). Silence in the second language classroom. Baisingstoke, UK: Palgrave Macmillan.

King, J. (2014). Fear of the true self: Social anxiety and the silent behaviour of Japanese learners of English. In K. Csizér \& M. Magid (Eds.), The impact of self-concept on language learning (pp. 232-249). Clevedon, UK: Multilingual Matters.

King, J. (2016). Classroom silence and the dynamic interplay between context and the language learner: A stimulated recall study. In J. King (Ed.), The dynamic interplay between context and the language learner (pp. 127-150). Basingstoke, UK: Palgrave Macmillan. 
King, J., \& Aono, A. (2017). Talk, silence and anxiety during one-to-one tutorials: A crosscultural comparative study of Japan and UK undergraduates' tolerance of silence. Asia Pacific Education Review, 18(4), 489-499. doi:10.1007/s12564-017-9503-8

King, J., \& Smith, L. (2017). Social anxiety and silence in Japan's tertiary foreign language classrooms. In C. Gkonou, M. Daubney \& J. M. Dewaele (Eds.), New insights into language anxiety: Theory, research and educational implications (pp. 91-109). Bristol, UK: Multilingual Matters.

King, J., Yashima, T., Humphries, S., Aubrey, S. \& Ikeda, M. (2020). Silence and anxiety in the English-medium classroom of Japanese universities: A longitudinal intervention study. In J. King \& S. Harumi (Eds.), East Asian perspectives on silence in English language education (pp. 60-79). Bristol, UK: Multilingual Matters.

Kirmayer, L. J. (1991). The place of culture in psychiatric nosology: Taijin kyofusho and DSM-III-R. Journal of Nervous and Mental Disease, 179(1), 19-28. doi:10.1097/00005053-199101000-00005

Kondo, D. S., \& Ying-Ling, Y. (2004). Strategies for coping with language anxiety: The case of students of English in Japan. ELT Journal, 58(3), 258-265. doi:10.1093/elt/58.3.258

Kusaka, J., A. (2013). Silence in the classroom can be golden. In N. Sonda \& A. Krause (Eds.), JALT2012 Conference proceedings (pp. 410-419). Tokyo: JALT.

Lebra, T. S. (1987). The cultural significance of silence in Japanese communication. Multilingua, 6(4), 343-357. doi:10.1515/mult.1987.6.4.343

MacIntyre, P. D., \& Dewaele, J. M. (2014). The two faces of Janus? Anxiety and enjoyment in the foreign language classroom. Studies in Second Language Learning and Teaching, 4(2), 237-274. doi:10.14746/ssllt.2014.4.2.5

Maftoon, P., \& Ziafar, M. (2013). Effective Factors in Interactions within Japanese EFL Classrooms. The Clearing House: A Journal of Educational Strategies, Issues and Ideas, 86(2), 74-79. doi:10.1080/00098655.2012.748641

Matsuda, S., \& Gobel, P. (2004). Anxiety and predictors of performance in the foreign language classroom. System, 32(1), 21-36. doi:10.1016/j.system.2003.08.002

Matsumoto, D. (1993). Ethnic differences in affect intensity, emotion judgments, display rule attitudes, and self-reported emotional expression in an American sample. Motivation and Emotion, 17(2), 107-123. doi:10.1007/bf00995188

McVeigh, B. J. (2002). Japanese higher education as myth. New York, NY: M.E. Sharpe.

Nakane, I. (2007). Silence in intercultural communication: Perceptions and performance. Philadelphia, PA: John Benjamins. 
Nation, P. (1997). L1 and L2 use in the classroom: A systematic approach. TESL Reporter, 30(2), 19-27. Retrieved from https://www.wgtn.ac.nz/lals/resources/paulnations-publications/paul-nations-publications/publications/1997-L1-L2.pdf

Neale, J. (2016). Iterative categorization (IC): a systematic technique for analysing qualitative data. Addiction, 111(6), 1096-1106. doi:10.1111/add.13314

Nishino, T., \& Watanabe, M. (2008). Communication-oriented policies versus classroom realities in Japan. TESOL Quarterly, 42(1), 133-138. doi:10.1002/j.1545-

7249.2008.tb00214.x

Osterman, G. L. (2014). Experiences of Japanese university students' willingness to speak English in class: A multiple case study. SAGE Open, 4(3), 1-13.

doi:10.1177/2158244014543779

Peak, L. (1989). Learning to become part of the group: The Japanese child's transition to preschool life. Journal of Japanese Studies, 15(1), 93-123. doi:10.2307/132409

Peng, J. E. (2012). Towards an ecological understanding of willingness to communicate in EFL classrooms in China. System, 40, 203-213. doi:10.1016/j.system.2012.02.002

Richards, K. (2003). Qualitative inquiry in TESOL. Baisingstoke, UK: Palgrave Macmillan.

Saville-Troike, M. (1985). The place of silence in an integrated theory of communication. In D. Tannen \& M. Saville-Troike (Eds.), Perspectives on silence (pp. 3-18). New Jersey, NJ: Ablex Publishing.

Scherer, K. R., Clark-Polner, E., \& Mortillaro, M. (2011). In the eye of the beholder? Universality and cultural specificity in the expression and perception of emotion. International Journal of Psychology, 46(6), 401-435. doi:10.1080/00207594.2011.626049

Scollon, R. (1985). The machine stops: Silence in the metaphor of malfunction. In D. Tannen \& M. Saville-Troike (Eds.), Perspectives on silence (pp. 21-30). New Jersey, NJ: Ablex Publishing.

Senior, R. M. (2006). The experience of language teaching. Cambridge, UK: Cambridge University Press.

Shachter, J. M. (2018). Tracking and quantifying Japanese English language learner speaking anxiety. The Language Teacher, 42(4), 3-7. doi:10.37546/jalttlt42.4-1

Shea, D. P. (2017). Compelled to speak: Addressing student reticence in a university EFL classroom. The Asian Journal of Applied Linguistics, 4(2), 173-184. Retrieved from https://caes.hku.hk/ajal/index.php/ajal/article/view/451

Sobkowiak, W. (1997). Silence and markedness theory. In A. Jaworski (Ed.), Silence: Interdisciplinary perspectives (pp. 39-62). New York, NY: Mouton de Gruyter. 
Squires, A. (2009). Methodological challenges in cross-language qualitative research: A research review. International Journal of Nursing Studies, 46(2), 277-287. doi:10.1016/j.ijnurstu.2008.08.006

Tani-Fukuchi, N. (2005). Japanese learner psychology and assessment of affect in foreign language study. The Language Teacher, 29(4), 3-9.

Tannen, D. (1985). Silence: Anything but. In D. Tannen \& M. Saville-Troike (Eds.), Perspectives on silence (pp. 93-111). New Jersey, US: Ablex Publishing.

Topham, P., Moller, N., \& Davies, H. (2016). Social anxiety in learning: stages of change in a sample of UK undergraduates. Journal of Further and Higher Education, 40(1), 125-145. doi:10.1080/0309877x.2014.895307

Toyama, M., \& Yamazaki, Y. (2018). Exploring the components of the foreign language classroom anxiety scale in the context of Japanese undergraduates. Asian-Pacific Journal of Second and Foreign Language Education, 3(4), 1-27. doi:10.1186/s40862018-0045-3

Williams, K. E., \& Andrade, M. R. (2008). Foreign language learning anxiety in Japanese EFL university classes: Causes, coping, and locus of control. Electronic Journal of Foreign Language Teaching, 5(2), 181-191. Retrieved from https://eflt.nus.edu.sg/v5n22008/williams.pdf

Wragg, E. C. (1999). An introduction to classroom observation. London, UK: Routledge. 